\title{
Both Feminist and Practical Politics: The Incorporation of Infertility Treatment into Family Planning in Britain, 1930s-1950s
}

\section{Laura Beers}

\begin{abstract}
In the mid-twentieth century, the Family Planning Association emerged in Britain as one of the largest providers of infertility diagnosis for men and women. In the early years of the century, women were coming to birth control centers seeking cures for their childlessness, well before those centers began officially offering infertility investigation and treatment. What changed by mid-century was the emergence of a determination not only to welcome infertility patients at birth control clinics but to establish the clinics as centers for infertility research and care. Beginning in the late 1930s, eugenicists concerned with the impact of population decline on the social acceptability of birth control formed an alliance with feminist medical professionals determined both to empower women in involuntarily childless marriages to understand and address the causes of their infertility and to shift the paradigm of infertility treatment away from its over-focus on the female body. This political marriage of convenience gave birth to a large-scale movement to diagnose both male and female infertility through the auspices of the Family Planning Association. The organization's infertility program, in turn, spurred the development of infertility as a field of medical research in postwar Britain and encouraged the expansion of National Health Service provision of infertility care.
\end{abstract}

n 1982, the Family Planning Association (also known as the FPA) began its evidentiary submission to the Warnock Committee of Inquiry into Human Fertilization and Embryology by emphasizing, "The FPA is an organization promoting family-building and the care of families as well as of individuals. Involuntary childlessness is therefore as much the FPA's concern as fertility control and the prevention of unintended conceptions." "Yet this concern for what came to be known as the "positive side" of family planning had not always been a part of the association's agenda, nor had promoting family building been a concern of the

Laura Beers is professor of history at American University in Washington, DC. She thanks the participants at the Johns Hopkins University History of Medicine Colloquium, the North American Conference on British Studies, and the Society for the Social History of Medicine Conference, as well as the journal's anonymous referees, for their feedback on earlier drafts of this article. Research for the article was funded by the Wellcome Trust (210281/Z/18/Z). Please direct any correspondence to beers@american.edu.

${ }^{1}$ Outline of FPA evidence to the Inter-Departmental Inquiry into Artificial Reproduction [the association's misnomer for the Committee of Inquiry into Human Fertilisation and Embryology], 9 December 1982, SA/FPA/C/B/4/13/1, Family Planning Association papers, Wellcome Library, London (hereafter FPA papers). 
organization in recent years. Rather, the comparatively brief marriage of birth control and infertility treatment under the umbrella of the Family Planning Association was a historically specific consequence of the dual pressures of eugenic and feminist politics on the organization in the middle decades of the twentieth century.

Beginning in the late 1930s, eugenicists concerned with the impact of population decline on the social acceptability of birth control formed what was at times an uneasy alliance with feminist medical professionals determined both to empower women in infertile marriages and to shift the paradigm of infertility treatment away from its over-focus on the female body. This political marriage of convenience gave birth to a large-scale movement to diagnose both male and female infertility through the auspices of the Family Planning Association. The association's investment in infertility diagnosis was, in turn, instrumental in the development of infertility as a field of medical research in postwar Britain and important to the expansion of National Health Service provision of infertility care. The alliance had lasting consequences for the association's policy, which, as the opening quotation illustrates, remained committed to addressing involuntary childlessness into the 1980s. It was only another contingent development - the simultaneous emergence of second-wave feminism and new reproductive technologies such as in vitro fertilization - that shifted the political balance of power within the organization away from a commitment to the so-called positive side of family planning and back toward an exclusive focus on "fertility control and the prevention of unintended conceptions." In this discussion of the role of feminists and eugenicists in forwarding infertility treatment within the mid-century Family Planning Association, I eschew an overdetermined reading of medical progress, arguing that the expansion of infertility treatment in that period was intimately contingent upon and interwoven within broader social and political developments.

\section{TOWARD A POLITICAL HISTORY OF INFERTILITY TREATMENT IN MODERN BRITAIN}

In the introduction to the 2018 Palgrave Handbook of Infertility in History, Gayle Davis and Tracey Loughran noted that the study of infertility has tended to be "present-minded," dominated by "a wealth of outstanding ethnographic research . . .

\footnotetext{
${ }^{2}$ Much more remains to be written on the contested relationship of second-wave feminism to infertility advocacy. From the perspective of the history of the Family Planning Association, by the time the charity was placed into liquidation on 15 May 2019, the association had apparently become openly skeptical of infertility activism - a reflection, arguably, of a political culture that increasingly sees the promotion of fertility treatment as in conflict with a pro-choice feminist politics. In an interview on 16 April 2018, Adam Balen, past president of the British Fertility Society and chair of the Fertility Education Initiative, indicated that the association was chary of the Fertility Education Initiative's remit to have fertility education included in the new Sex and Relationship Curriculum and declined to collaborate. On second-wave feminism and infertility more broadly, see Jane Lewis and Fenella Cannell, "The Politics of Motherhood in the 1980s: Warnock, Gillick, and Feminists," Journal of Law and Society 13, no. 3 (1986): 321-42, at 321; Tracey Loughran, "Conditions of Illusion: Agency, Feminism, and Cultural Representations of Infertility in Britain, c. 1960-80," in The Palgrave Handbook of Infertility in History, ed. Gayle Davis and Tracey Loughran (Basingstoke, 2018), 431-49. In the United States, feminist Gloria Steinham has been an outspoken critic of recent New York state legislation to legalize surrogacy, which has been promoted by infertility lobbying groups such as Resolve. See Vivian Wang, "Surrogate Pregnancy Battle Pits Progressives against Feminists," New York Times, 12 June 2019, https://www.nytimes.com/2019/06/12/nyregion/surrogate-pregnancy-law-ny.html.
} 
on experiences of infertility and related issues in diverse local, national and global contexts." 3 In Britain, this body of scholarship includes the pathbreaking work done by the anthropologist Sarah Franklin and the psychologist Susan Golombok on the impact of artificial reproductive technologies on family and identity in modern Britain, which in turn has inspired the work of a new generation of social science researchers. ${ }^{4}$ Ethnographic studies of infertility and its treatment, in Britain and internationally, have been self-consciously political, if we define reproductive politics in its broadest Foucauldian sense as a "set of themes, cultural ideas, and power relationships undergirding controversial reproductive issues." ${ }^{5}$ Both social scientists and historians of infertility have seen in discourses on and treatments of infertility a tendency to reduce feminine power and agency by pathologizing the infertile female body. ${ }^{6}$ However, if we switch the question from "What is political about the history of infertility?" to "How can we write a political history of infertility?," the perspective changes.

As a political historian, I am interested in what the provision (or lack thereof) for infertility research and treatment reveals about the changing relationship between individuals, family, the state, and civil society. How have Britons viewed infertility as a problem affecting the body politic versus a personal problem affecting individuals in the private family sphere, and how this has changed over time? What can arguments about the availability of and entitlement to infertility treatment tell us about conceptions of individual rights and notions of "worthiness"? How have debates over the provision of infertility treatments been gendered, racialized, or approached from the perspective of class or eugenics?7 And what can this tell us about British political culture and society more broadly?

\footnotetext{
3 Tracey Loughran and Gayle Davis, "Introduction: Infertility in History: Approaches, Contexts and Perspectives," in Davis and Loughran, Palgrave Handbook of Infertility, 1-25, at 3.

${ }^{4}$ Sarah Franklin's first book, Embodied Progress: A Cultural Account of Assisted Conception (London, 1997), remains a key text in the field. Her more recent publications include Biological Relatives: IVF, Stem Cells and the Future of Kinship (Durham, 2013). See also Susan Golombok, Modern Families: Parents and Children in New Family Forms (Cambridge, 2015); Kylie Baldwin, "I Suppose I Think to Myself, That's the Best Way to Be a Mother': How Ideologies of Parenthood Shape Women's Use of Social Egg Freezing Technology," Sociological Research Online 22, no. 2 (2017): 20-34; Lucy van der Wiel, "Bevroren Vruchtbaarheid/Frozen Fertility," Tijdschrift voor Genderstudies 19, no. 2 (2016): $286-88$.

${ }^{5}$ Liberty Walther Barnes, Conceiving Masculinity: Male Infertility, Medicine, and Identity (Philadelphia, 2014), 155.

${ }^{6}$ In Making Sex: Body and Gender from the Greeks to Freud (Cambridge, MA, 1992), Thomas Laqueur posited the two-sex model of human sexuality, with its attendant pathologization of the lesser female body, as a distinct phenomenon of modernity. Since its publication, a large body of scholarship has emerged showing that infertility and other sexual and reproductive dysfunction (including female hysteria) has been historically attributed to the pathologized female body in the modern period. For a discussion of this literature, see Stephanie E. Libbon, "Pathologizing the Female Body: Phallocentrism in Western Science," Journal of International Women's Studies 8, no. 4 (2007): 79-92. Christina Benninghaus's recent work is comparatively rare in pushing back against this reading of infertility medicine. See her "Beyond Constructivism?: Gender, Medicine and the Early History of Sperm Analysis, Germany 18701900," Gender and History 24, no. 3 (2012): 647-76.

${ }^{7}$ My focus in this paper is domestic British history in the 1930s and 1950s, before the surge in Commonwealth immigration; I do not explicitly address race, which was not discussed in the papers that survive in the Family Planning Association archive. A history of infertility in Britain and the British Empire that properly treats race remains to be written.
} 
In the introduction to his now classic investigation of the popularization of Louis Pasteur's ideas in nineteenth-century France, Bruno Latour sought to do away with the "superfluous hypothesis" that science is a discipline "independent of politics," arguing instead that "science' and 'society' are both explained more adequately by an analysis of the relations among forces and that they become mutually inexplicable and opaque when made to stand apart." 8 The science of infertility is no different from the science of microbiology and immunology in that respect. How, this article asks, has the political context in which scientific and medical professionals researched infertility and treated infertility patients shaped their practice?

Recent scholarship has begun to explore these questions, but there is much more work to be done. In her 1993 study of the politics of infertility within the British medical profession, Naomi Pfeffer focused on the central role of political economy in explaining the development of infertility treatment in Britain. Pfeffer argued that the early development of state-funded medical care under the 1911 National Health Insurance Scheme marginalized the treatment of infertility by limiting care to the insured male breadwinner. Following the development of the National Health Service in 1948 and the expansion of health care to all women, she contended, the government evaded putting resources into infertility services through a threepronged policy of "abstinence; postponement; and depoliticization," until the coincident development of in vitro fertilization and private medical care in Britain in the late 1970s saw the explosion of infertility treatment outside the NHS. ${ }^{9}$

Pfeffer's work focused on the ways in which cultural prejudices and economic imperatives drove political logics behind decisions over state funding of infertility treatment. Davis has explored how cultural prejudices against women as irrational or hysterical weighed alongside legal concerns about the risk of incest and possible threats to inheritance law on the one hand, and the right to privacy on the other, in the protracted deliberations of the Feversham commission on artificial insemination established in September 1958. ${ }^{10}$ Hayley Andrews's unpublished doctoral dissertation has also examined the debates of the Feversham committee, with an eye to what "the discourse of infertility and assisted conception" and its "focu[s] on marriage, class, and gender roles" could reveal about "broader anxieties over the divorce rate, 'problem families', and changing notions of masculinity and femininity."11 Andrews's research, like this article, highlighted the role of the Eugenics Society in pushing the Family Planning Association to expand its sub-fertility work. Caroline Rusterholz's work on British and French female doctors' approach to family planning in the mid-century has explored gendered differences in understandings of sexuality and reproduction in this period and the importance of feminist politics to these women's approach to reproductive medicine. Rusterholz contends that women doctors were important advocates for a female-centered medical practice in birth

\footnotetext{
${ }^{8}$ Bruno Latour, The Pasteurization of France, trans. Alan Sheridan and John Law (Cambridge, MA, 1993), 7.

${ }^{9}$ Naomi Pfeffer, The Stork and the Syringe: A Political History of Reproductive Medicine (London, 1993), 94.

${ }^{10}$ Gayle Davis, “'A Tragedy as Old as History': Medical Responses to Infertility and Artificial Insemination by Donor in 1950s Britain," in Davis and Loughran, Palgrave Handbook of Infertility, 359-82.

${ }^{11}$ Hayley Andrew, "The Reluctant Stork: Science, Fertility and the Family in Britain, 1943-1960" (PhD diss., York University, 2016), 372.
} 
control, infertility, and sex counseling in this period, aimed at giving women control over their sexuality and reproductive decision-making. ${ }^{12}$

The American authors Margaret Marsh and Wanda Ronner have argued that "changes in culture, rather than scientific advances or greater technological expertise, have been and still are the forces most likely to bring a rush of infertility patients to clinicians' offices." 13 The same could be said for the forces driving the provision of infertility treatment. Demand for infertility treatment was not wanting in early twentieth-century Britain. As we shall see, women were coming to birth control centers seeking cures for their childlessness well before those centers began officially offering infertility investigation and treatment. What changed in the mid-twentieth century was the emergence of a determination not only to welcome infertility patients at birth control clinics but to establish these clinics as centers for infertility research and care. Ultimately, the Family Planning Association's commitment to treating infertility patients would spur advances in the field, but it was the political context, not developments in medical practice, that brought the association into infertility work.

Scholars in other national contexts have also explored the relationship between politics, state and non-governmental actors, and infertility in the twentieth century. Fabrice Cahen has traced the tensions between pronatalist imperatives, centralizing tendencies within the postwar French welfare system, and funding limitations in shaping the contours of the state-funded infertility sector. ${ }^{14}$ Bridget Gurtler's unpublished history of artificial insemination in the United States pays particular attention to the role of World War II veterans in recasting public perceptions of male sterility as a legitimate medical condition and lobbying the government to commit resources to its investigation and treatment. ${ }^{15}$ In this article I build on this existing body of research through a focus on how the political agendas of both eugenicists and feminists within the family planning movement converged to encourage a rapid expansion of infertility work by the Family Planning Association in the 1940s, which, in turn, spurred both greater government investment in infertility and an expansion of scientific research in the field.

Despite the fact that the organization played a key role in research and treatment of infertility in the mid-twentieth century, histories of the association have given little attention to this aspect of the organization's work. Audrey Leathard's The Fight for Family Planning only briefly mentions infertility, and Stephen Brooke's otherwise excellent Sexual Politics: Sexuality, Family Planning and the British Left relies heavily on the papers of the association but includes no reference to its work with the involuntarily childless. ${ }^{16}$ The role of eugenicists in the development of the family planning

\footnotetext{
${ }^{12}$ Caroline Rusterholz, "English and French Women Doctors in International Debates on Birth Control (1920-1935)," Social History of Medicine 31, no. 2 (2018): 328-47.

${ }^{13}$ Margaret Marsh and Wanda Ronner, The Empty Cradle: Infertility in America from Colonial Times to the Present (Baltimore, 1996), 3.

${ }^{14}$ Fabrice Cahen, "Obstacles to the Establishment of a Policy to Combat Infertility in France, c. 19201950," in Davis and Loughran, Palgrave Handbook of Infertility, 199-219.

${ }^{15}$ Bridget Gurtler, "Synthetic Conception: Artificial Insemination and the Transformation of Reproduction and Family in Nineteenth and Twentieth Century America" (PhD diss., Rutgers University, 2013), chap. 3.

${ }^{16}$ Audrey Leathard, The Fight for Family Planning: The Development of Family Planning in Britain, 192174 (London, 1980); Stephen Brooke, Sexual Politics: Sexuality, Family Planning and the British Left from the 1880s to the Present Day (Oxford, 2011).
} 
movement, and particularly its program of infertility treatment, has also received insufficient attention. ${ }^{17}$ Similarly, the centrality of female doctors to the expansion of infertility work has only recently received scholarly attention. ${ }^{18}$ This contemporary and historiographical amnesia reflects the shift in focus of the association's work from the 1980s but obscures a crucial aspect of the organization's early history-an aspect that, when scrutinized, reveals much about the social and political culture that drove the development of infertility research and treatment in the period.

\section{UNDERSTANDINGS OF INFERTILITY IN 1930 S BRITAIN}

By the early twentieth century, it was medically accepted that pregnancy required the production of a healthy ovum and its transport down a woman's fallopian tube, followed by insemination by a sperm that had successfully traveled up through a woman's cervix, and implantation in a receptive womb. Anovulation, tubal occlusion, a damaged or malformed cervix, and a prolapsed uterus were all recognized as causes of infertility (or sterility, to use the term more common at the time) in women. While estimates varied, a significant percentage of tubal and uterine damage was attributed to venereal disease. ${ }^{19}$

In addition to problems with the female reproductive system, interwar medical practitioners recognized that approximately half of all infertility within heterosexual partners could be attributed to the male. Oligospermia (low sperm count), azoospermia (complete absence of sperm), low motility, abnormal morphology, or physiological factors such as obstructions to the vas deferens, which connect the testes to the urethra, can all contribute to male-factor infertility. Yet it was not until after the Second World War that it became routine practice to test both parents in a childless marriage for indicators of infertility before proceeding with treatment.

\footnotetext{
${ }^{17}$ While biographers of Marie Stopes have highlighted her links to eugenics, Leathard's history of the Family Planning Association is vague on the central role of the Eugenics Society in funding the organization in its early years. Andrew's dissertation highlights the importance of the "ambiguous relationship" between the Eugenics Society and the Family Planning Association, noting, "The shared membership and financial relationship of these two organizations points to an important intersection, with implications for the aims of the FPA in this period" (Andrew, "Reluctant Stork," 5-6). Emma Jones has looked at the role of eugenicists in the establishment of the Mothers' Welfare Clinic in Liverpool in 1926, in Emma L. Jones, "Family Planning Clinics in Liverpool and Bradford, 1926-1930: A Comparative Study," Social History of Medicine 24, no. 2 (2011): 352-69. Clare Makepeace has explored the relationship between feminists and eugenicists in the promotion of birth control, but not in reference to infertility: Clare Makepeace, "To What Extent Was the Relationship between Feminists and the Eugenics Movement a 'Marriage of Convenience' in the Interwar Years?," Journal of International Women's Studies 11, no. 3 (2007): 65-80.

${ }^{18}$ Caroline Rusterholz, Women's Medicine, Sex, Family Planning and British Female Doctors in Transnational Perspective, 1920-70 (Manchester 2020), chap. 2.

${ }^{19}$ Anne Hanley, “"The Great Foe to the Reproduction of the Race': Diagnosing and Treating Infertility Caused by Venereal Diseases, 1880-1914," in Davis and Loughran, Palgrave Handbook of Infertility, 33558. Recently, Simon Szreter and Kevin Schürer have reconsidered Edwardian social survey data with an eye to determining the actual impact of sexually transmitted infections on prewar fertility; they conclude that, while the impact of syphilis may have been overstated, gonorrhea and chlamydia likely played a significant role in secular fertility decline. See Simon Szreter and Kevin Schürer, "Revealing the Hidden Affliction: How Much Infertility Was Due to Venereal Disease in England and Wales on the Eve of the Great War?," in Hidden Affliction: Sexually Transmitted Infections and Infertility in History, ed. Simon Szreter (Rochester, 2019), 373-95.
} 
As early as 1883, J. Matthews Duncan began a series of lectures delivered to the Royal College of Physicians on "Sterility in Women" with the assertion

\begin{abstract}
I myself have found that the male was deficient in one example in eight... The matter is, however, still in a very insecure state, as may be shown by a statement of facts and consideration which must have important bearings on the question, but which have, so far as I know, been entirely neglected . . . It is held that the man is not at fault if he duly ejaculates microscopically perfect semen, but this is certainly not a warranted conclusion. . . In making estimates of male sterility, no account is taken of the fact that the faulty condition of a man's semen may be only temporary. It is forgotten that sterility may be due to faults in the semen, even though conception has taken place and pregnancy been established; the foetus fading and dying prematurely from inscrutable causes, or being monstrous and not viable, or perishing from disease implanted in it by the male. It is forgotten that both parents may be simultaneously at fault, and this with or without discoverable cause, generally without discoverable cause. ${ }^{20}$
\end{abstract}

In the decades that followed, limited progress was made in discerning how or why seemingly "microscopically perfect semen" might be infertile, but the practice of investigating semen under the microscope did become more commonplace. The biggest innovation came from the American gynecologist Max Huhner, who popularized the practice (first pioneered by another American, J. Marion Sims, in the 1860s) of investigating semen ejaculated into female cervical mucus to test their viability and motility in the cervical environment. ${ }^{21}$ In 1919, the British gynecologist Arthur Giles published Sterility in Women out of "public duty" as a contribution to ameliorating the postwar population crisis. Despite the title of his treatise, Giles was under no illusion that women were solely responsible for barren marriages. His first chapter was titled "Man's Share of Responsibility for Childless Marriages." Citing Huhner's recently published work, he estimated that about half of all cases of childless marriage were attributable to male-factor infertility, although he cited several studies that placed male "blame" higher due to their role in infecting their wives with sexually transmitted diseases such as gonorrhea that could render them sterile. Giles ended his chapter by underscoring that "the wife should not be assumed to be responsible. . . and submitted to operative procedures, without obtaining definite evidence that the husband is healthy." 22 Nor was acknowledgment of the male role in infertility in Britain limited to elite medical treatises. In her 1919 bestseller Married Love, Marie Stopes wrote of infertility, "It is now beginning to be recognized that in a childless union the 'fault', if fault it be, is as often the man's the woman's."23

\footnotetext{
${ }^{20}$ J. Matthews Duncan, On Sterility in Women, Being the Gulstonian Lectures Delivered in the Royal College of Physicians in February 1883 (London, 1884), 3-4.

${ }^{21}$ Marsh and Ronner, Empty Cradle, 102. Sims, who in 1855 founded the first American Women's Hospital in New York City, is much better known within medical literature for his problematic experimentations in fistula surgery on enslaved African-American women. Three years ago, New York City officials decided to remove a statue of Sims in Central Park in recognition of his problematic legacy. Camila Domonosky, "Father of Gynecology,' Who Experimented on Slaves, No Longer on Pedestal In NYC," NPR, 17 April, 2018, 1:39pm, https://www.npr.org/sections/thetwo-way/2018/04/17/603163394/father-of-gynecology-who-experimented-on-slaves-no-longer-on-pedestal-in-nyc $t=1580908869395$.

22 Arthur E. Giles, Sterility in Women (London, 1919), 12.

${ }^{23}$ Marie Stopes, Married Love (1918; repr., London, 1942), 123.
} 
Giles's discussion of best practice for British infertility doctors aligns with that of infertility specialists in the United States and Europe in this period. In her discussion of semen testing in nineteenth-century Germany, Christina Benninghaus concludes that "its acceptance seems to have increased considerably during the 1870s and 1880s . . . Apparently, public awareness of the possibility of male sterility and the usefulness of sperm testing increased, while individual resistance faltered . . By 1900, 'conscientious gynaecologists' were reported to refrain from the examination of women, 'before the husband's sperm had been analysed." 24 According to Marsh and Ronner, American infertility specialists in the interwar period had "establish[ed] a similar pattern of physical examination followed by laboratory tests. Both partners had their medical history taken, next undergoing a general physical that included urine and blood analyses. The wife's gynecological examination followed, then evaluation of the husband's semen for quantity, motility, and morphology."25

These ideal practices were not, however, necessarily widely realized. Among elite New York gynecologists, "the recalcitrant husband who refused semen testing became a staple of doctors' anecdotes. For every loving husband who wished to spare his wife unnecessary surgery, there were more who took umbrage at the imagined insult to their virility. . . Such attitudes on the part of husbands led many physicians simply to give up on the idea of demanding sperm samples."26 At Margaret Moore White's clinic at the Royal Free Hospital in London in the interwar period, only two out of three husbands consented to a semen analysis. Even when men were willing, only fifteen out of twenty-seven London hospitals and forty-nine out of ninety-four outside the capital in 1944 claimed to have facilities for investigating male fertility. ${ }^{27}$ There was thus little guarantee that women who sought treatment for infertility (and it was nearly always women who took the initiative on this front) could expect that their husbands would be properly evaluated. As H. S. Forsdike, gynecological surgeon at the Women's Hospital in Soho Square, noted, "It seems to be a law amongst the artisan class that it is always the woman who is at fault, and much unhappiness and even persecution [and presumably also medical intervention] is endured by the wife. . . in consequence." 28

While White and Forsdike write about their observations of hospital clinic patients, most of whom were working-class, ${ }^{29}$ the vast majority of wives in childless marriages did not turn to hospital treatment. Middle-class women might seek treatment at private gynecological practices, where, oftentimes, the same surgeons who saw working-class women in crowded hospital clinics would offer more intimate consultations at a considerable fee. Other women from across the social spectrum might consult their general practitioners. Many, many more took no action, simply putting their infertility down to fate. In 1944, the social research project Mass-Observation conducted a study titled The Reluctant Stork/Empty Quivers, for which they

${ }^{24}$ Benninghaus, "Beyond Constructivism," 145-46.

${ }^{25}$ Marsh and Ronner, Empty Cradle, 157.

${ }^{26}$ Marsh and Ronner, 102.

${ }^{27}$ Figures from Pfeffer, Stork and the Syringe, 57-58.

${ }^{28}$ Pfeffer, $57-58$.

${ }^{29}$ For a recent discussion of patients and funding structures in interwar voluntary hospitals, see George Campbell Gosling, "The Patient Contract in Bristol's Voluntary Hospitals, c.1918-1929," University of Sussex Journal of Contemporary History, no. 11 (2007): 1-16. 
interviewed, among others, ninety-eight women who had borne only one child, and found that the vast majority would have preferred to have more children. Yet few had sought help for their "sub-fertility." The Mass-Observation report attributed this to the "frequent defeatist attitude of working-class women towards their own incapacity to bear children." 30 In a separate report, published the following year, the authors wrote of their interviews of couples facing sterility and sub-fertility: "The most common response was . . . that fatalistic 'what you've dotted out for you have."'31

\section{INFERTILITY TREATMENT IN INTERWAR BIRTH CONTROL CLINICS}

Over the course of the 1930s, an increasing number of infertile or sub-fertile working-class women reluctant to consult their general practitioners or to visit a hospital clinic turned to family planning centers for advice and treatment. During the interwar years, a range of such centers including entirely voluntary facilities opened their doors in Britain, and, after July 1930, both municipal clinics and voluntary clinics were funded through municipal grants. ${ }^{32}$ The majority of voluntary clinics were affiliated with the National Birth Control Association (the Family Planning Association was known as the National Birth Control Association until 1939, on which more below), with another five regional Mothers' Clinics (and two traveling caravans) run by Marie Stopes and her husband.

Earlier scholarship took a comparatively hostile view of Stopes's Mothers Clinics as being tainted by her association with the eugenics movement; however, more recent work has emphasized Stopes's feminist commitment and pointed out that she treated poorer patients with compassion and respect. ${ }^{33}$ In many respects, Stopes, whose clinics were staffed by women doctors, was little different from the avowedly feminist women who staffed many of the association's clinics in the 1930s (many of whom were also affiliated with the eugenics movement). While wide variations existed between different types of clinics and similarly funded clinics in different localities, for the most part family planning clinics in the 1930s saw their mission as the fitting and distribution of female contraceptive devices

${ }^{30}$ The Reluctant Stork/Empty Quivers, Mass-Observation File Report 2182 (London, 1944), 15, MassObservation archive, Sussex, UK, via Adam Matthew Digital, accessed January 19, 2021, http://www.massobservation.amdigital.co.uk.libproxy.york.ac.uk/Documents/Details/FileReport-2182. Angela Davis found that this fatalistic approach to subfertility persisted among mothers in postwar Oxfordshire. See her chapter "Oral History and Women's Accounts of Infertility in Postwar England," in Davis and Loughran, Palgrave Handbook of Infertility, 123-42.

${ }^{31}$ Mass-Observation, Britain and Her Birthrate (London, 1945), 108.

${ }^{32}$ In July 1930, the government issued Memo 153/MCW, which permitted local authorities to provide information on birth control to married women. Most, if not all, of these municipal grants went to the association's clinics. (I have yet to find evidence of a non-association clinic receiving a municipal subsidy.)

${ }^{33}$ Deborah Cohen, "Private Lives in Public Spaces: Marie Stopes, the Mothers' Clinics and the Practice of Contraception," History Workshop Journal 35, no. 1 (1993): 95-116; Clare Debenham, Marie Stopes' Sexual Revolution and the Birth Control Movement (Basingstoke, 2018). While recent scholarly literature has cast Stopes in a more positive light, her alma mater, University College London, is moving to distance itself from her on account of her eugenicist links. See Robin McKie, "Top University Split in Row over Erasing 'Racist' Science Pioneers from the Campus, Guardian, 13 July 2019, https://www.theguardian. com/world/2019/jul/13/ucl-inquiry-row-historical-racism-science-pioneers-rename-college-buildings? $\mathrm{CMP}=$ share_btn_tw. 
(diaphragms), not the diagnosis and treatment of infertility. ${ }^{34}$ That said, both Marie Stopes's clinics and the National Birth Control Association clinics would occasionally treat infertility patients who came to them for advice.

As early as 1932, the Exeter branch of the association noted in its annual report, "A few patients have attended the Clinic for advice on account of involuntary sterility. This is a branch of constructive Birth Control in which we hope to do more work in the future." 35 During its first year and a half in operation (1926-1928), the Oxford clinic treated 125 patients, eight of whom were "childless women [who] asked for advice as to how they might have children." 36 According to the 1927 report of the Cambridge branch, "Among the interesting cases during the past year have been six patients who desired to have children, and who came to the Centre anxiously hoping that some treatment could be advised which would enable them to become mothers. These patients received most sympathetic attention from the medical officer [Mrs. Robson] who, after considering their cases, referred them to the hospital or to the proper specialist for appropriate treatment." 37 The report of the medical officer of the Guilford clinic in 1935 noted that many of the women visiting the clinic suffered from acute gynecological ailments that would make further pregnancy dangerous and that she was also consulted on "three cases of sterility and [by] three husbands wishing for advice."38

In a 1936 memorandum on the possibility of greater cooperation between the Eugenics Society and the National Birth Control Association, C. P. Blacker, the Eugenics Society's general secretary, noted, "The North Kensington Women's Welfare Centre, in addition to giving advice on contraception, has already enlarged its function by taking into account gynecological problems; most of the clinics, moreover, are occasionally consulted by sterile couples who desire to have children." 39 As Margery Spring Rice, the head of the North Kensington center, put it in 1939, "They had been forced into the constructive side of the work - it had never been their object to allow the principle of voluntary parenthood to be in any way submerged by other activities - these had been a natural development and added to the value of b.c. [birth control] in the eyes of the public, the women themselves and the medical profession. ${ }^{\prime 40}$ In other words, the clinics advertised themselves as offering birth control services, but women showed up with all kinds of problems.

\footnotetext{
${ }^{34}$ Much work remains to be done on the practice and social position of local clinics. Pamela Dale and Kate Fisher, "Contrasting Municipal Responses to the Provision of Birth Control Services in Halifax and Exeter before 1948," Social History of Medicine 23, no. 3 (2010): 567-85, have begun this task with their close analysis of documents from the municipally supported Exeter clinic and the privately funded clinic in Halifax (both were affiliated to the association). However, their conclusions, in my view, both overplay the eugenicist and culturally superior attitude of the Exeter clinic's leadership and discount the reality that the "strong links" between the Halifax clinic and the National Birth Control Association head office implicated the northern clinic in a broader national project funded and supported by eugenicists.

${ }^{35}$ Exeter and District Women's Welfare Association Anmual Report 1932, SA/FPA/A4, FPA Papers.

${ }^{36}$ Annual Report: 1926-1928, Oxford Family Welfare Association, 4 King St., Jericho, UK, SA/FPA/ A4, FPA papers.

${ }^{37}$ Annual Report: 1926-1927, Cambridge Women's Welfare Association second annual report, Birth Control Centre, Fitzroy Hall, Wellington St., SA/FPA/A4, FPA papers.

${ }^{38}$ Report of the Medical Officer of the Guilford Clinic, 1935, SA/FPA/A4, FPA papers.

${ }^{39}$ C. P. Blacker, "The Eugenics Society and the National Birth Control Association," 22 September 1936, SA/FPA/Al/1, FPA papers.

${ }^{40}$ Special Mtg, 10 May 1939, SA/FPA/Al/2, FPA papers.
} 
It was easy to understand how this developed. Both Stopes's Mothers' Clinics and the National Birth Control Association's clinics charged minimal fees on a sliding scale. While the latter's clinics strongly encouraged women to let them communicate with their family doctors, they did not mandate that they do so. Both clinics were run largely by women, and patients thus escaped the embarrassment of having their local, likely male, doctor examine them. The women who served at these clinics as medical officers had sufficient training in gynecology to diagnose symptoms of past or current venereal disease as well as certain anatomical indications of sterility. However, there were limits to the practical treatment that they could offer to patients.

In her 1923 book, Contraception: Its Theory, History and Practice, Marie Stopes wrote that her flagship London clinic handled "birth control from its broadest and truest aspect. . . [which] also implies the positive side, namely the inducement of conception where couples are childless and desire children and are themselves healthy. This positive side of the clinic's work, of course, requires a much wider knowledge than is necessary for the use of the simple contraceptive, and it is interesting that even in the short time that this aspect has been accentuated, a considerable number of persons desiring children have used the Clinic with benefit." 41 Unfortunately, Stopes felt that "in a book on contraception . . . as distinct from Constructive Birth Control, a discussion of this aspect of the Birth Control Clinic is out of place," and limitations on access to patient files mean that it is hard to establish what positive treatments Stopes's clinics offered patients, beyond the diagnosis of irremediable sterility due to venereal disease, or the correction of "some elementary lack of adjustment in the coital act." 42 Nonetheless, Stopes apparently felt sufficiently proud of her accomplishments in helping some couples to conceive that she hung pictures of their progeny in her clinic office. ${ }^{43}$

A report on the opening of the Mothers' Clinic in Cardiff reinforces the picture of infertility treatment as a regular, if not common, feature of clinic practice in the interwar period. Of the nearly three dozen patients seen at the clinic during its first month of operation in 1937, "three of the women coming were healthy married women wanting babies but had remained sterile. They have been examined and helped and we hope in due course will become pregnant." 44 The Marie Stopes records at the Wellcome Library include one file containing thirty-two case notes from clinics in Leeds, Aberdeen, and Belfast. Of these, two are for infertility patients. One, Mrs. B, who visited the Belfast clinic on 13 November 1936 and had been married since 12 June 1929, "consulted us as to why she had not had children." The clinic's diagnosis was "[illegible] and inflammation, vaginal discharge. Probably gonorrhea. Refuses to return to Dr. McKenzie [gynecologist at Samaritan Hospital for Women and Children, Belfast] for treatment. Have advised [illegible: P-onal??] pessaries and instructed patient to return." Another patient, Mrs. F, husband of a papermaker in Barnsley, visited the Leeds clinic on 7 October 1936, desiring a child. She was thirty-three and had been married seven years. Her records note that she was diagnosed with a "slight anteversion [of the cervix]" and was advised

${ }^{41}$ Marie Stopes, Contraception: Theory, History and Practice (London: John Bale, 1923), 388-89.

42 Stopes, Contraception, 389.

${ }^{43}$ Cohen, "Private Lives," 99.

${ }^{44}$ Cardiff: Notes on cases seen in clinic's first month 1937, PP/MCS/C.26, Marie Stopes papers, Wellcome Library, London. 
to "douche with sodium bicarbonate before Intercourse. To place pillow under back during intercourse. To see Dr. Frost as soon as convenient." 45 Unfortunately, the records do not indicate whether Mrs. F returned to see Frost, and what course of treatment, if any, Frost indicated. Both of these women were taken more seriously, it appears, than Mrs. S, an East End seamstress who visited the flagship Stopes clinic on Whitfield Street off Tottenham Court Road in the 1920s. Mrs. S had come to the clinic after seeing an ad in the Star that referenced the clinic's treatment of sterility patients. In an interview several decades later, she recalled that "some surprise was expressed that [she] at the age of 35 and with a husband 10 years older, should want to start a family, but, after the usual examination and questions about her periods, she was told there was nothing wrong with her, and to go home and not to worry because conception could happen at any time.” Mrs. S never did have a child. 46

While clinic doctors could and did carry out vaginal examinations using a speculum, and, if needed, suggest remedies where infertility could be attributed to "some elementary lack of adjustment in the coital act," treatment for infertility was largely carried out by gynecologists; most family-planning doctors were not qualified in gynecology, a field that remained formally male dominated. ${ }^{47}$ The principal form of surgical intervention was the "correction" of the cervix through curettage. Other interventions included treatment for tubal occlusion, which could be diagnosed using either a Rubin test (invented in 1919 by Isidor Rubin, in which air was forced through the fallopian tubes to test for obstruction), or a salpingogram (invented in 1925 by Sidney Forsdike, in which an iodine solution was injected into the tubes which were then x-rayed to visualize patency.) Due to both the cost of equipment and the medical expertise required to perform these diagnostic tests, both were effectively limited to hospital clinics in the interwar period. ${ }^{48}$

Surgical interventions, while widely practiced, were not widely effective, which perhaps explains the medical enthusiasm for newly discovered hormone treatments. These were prescribed to both men and women in the 1930s, even before the etiology of their impact on ovulation, menstruation, and sperm production was understood. ${ }^{49}$ As the London gynecologist Mary Barton wrote in a wartime pamphlet Why Doesn't the Wanted Baby Always Come?, "Nearly all cases of sterility and lowered fertility are treated sooner or later with what are know $[\mathrm{n}]$ as hormones ...

45 Selection of individual case sheets from Leeds, Aberdeen, and Belfast clinics ca. 1937, PP/MCS/C.13, Marie Stopes papers. Dr. Henrietta Frost was the clinic's medical officer. On Frost, see Caroline E. L. Walker, "Making Birth Control Respectable: The Society for Constructive Birth Control and Racial Progress, and the American Birth Control League in comparative perspective, 1921-1938” (PhD diss., University of Bristol, 2007), 234.

${ }^{46}$ Alan S. Parkes and Dee King, "The Mother's Clinic: The Third Marie Stopes Memorial Lecture," Journal of Biosocial Science 6 (1974): 163-82, at 174.

${ }^{47}$ Margaret Jackson was exceptional in that she practiced as the gynecological consultant at the Royal Devon and Exeter. However, she was not a fellow of the Royal College of Obstetricians and Gynaecologists, although the college made her a fellow ad eundem in 1970. See "Fellows ad eundem of the RCOG," Royal College of Obstetricians and Gynaecologists (website), accessed 19 January 2021, https://www. rcog.org.uk/en/about-us/membership/membership-categories/fellows-ad-eundem/. Among Family Planning Association doctors, Margaret Moore White, Kathleen Harding, and Hilda Lloyd were, exceptionally, fellows.

${ }^{48}$ Pfeffer, Stork, 62-65; Marsh and Ronner, Empty Cradle, 145.

${ }^{49}$ Pfeffer, Stork, 67-78. 
These are substances which are normally produced in the body by glands and other organs in sufficient amount to maintain health and fertility." 50 The pessary prescribed to the Belfast Mothers' Clinic patient in 1936 was likely a hormone supplement. Yet, while general practitioners could, and did, prescribe hormone therapies, others felt that this should be left to gynecologists. Thus, the most likely course of action when patients presented at interwar birth control clinics with infertility in the 1920s and 1930s was that taken by the Cambridge National Birth Control Association clinic: a vaginal examination, followed by a hospital referral.

\section{THE POSITIVE SIDE OF FAMILY PLANNING}

The decision to expand infertility treatment within National Birth Control Association-run clinics should be understood in the context of eugenic and feminist politics in the late 1930s. On 2 December 1938, association branch representatives came together for their annual meeting and discussed, inter alia, the place of gynecological services in their clinics. Such services were provided systemically by two of the association's London clinics and by the Exeter clinic (in special gynecological sessions), and ad hoc by other clinics. ${ }^{51}$ The delegates expressed a wish for more information from headquarters about increasing gynecological provision in their clinics, with the result that the association circulated a memo to all branches shortly afterward underscoring the need for such services given high rates of maternal and post-partum sickness and mortality. "It is evident," they stressed, "that voluntary effort is needed to supplement the action of the Public Health Authorities; and everything points to action being taken by the already established voluntary birth control clinics." Headquarters provided information to the branches on the gynecological sessions offered by the London clinics and crucially noted that "out of 587 patients attending [one] gynaecological clinic, $10 \%$ were seeking advice because they wanted children." ${ }^{52}$

The National Birth Control Association doctors who attended the 1938 meeting were primarily women, a few with established hospital practices in obstetrics, who volunteered their time to the organization for little or no compensation. Generationally, most were born around the turn of the century and studied for their medical degrees after the First World War, although some, such as Helena Wright, were among the small cohort of women trained in medicine in the Edwardian period. Most were members of the Medical Women's Federation, an association for women doctors set up in 1879 when women were not yet admitted to either the British Medical Association or the professional colleges. ${ }^{53}$ Rusterholz has written about how women including Wright, Margaret Jackson, Joan Malleson, and Margaret Moore White played a foundational role in the dissemination of contraceptive

\footnotetext{
${ }^{50}$ Mary Barton, Why Doesn't the Wanted Baby Always Come? (London, n.d.), SA/FPA/A3/20/21: 1949_ 50 Sub-Fertility: General correspondence, FPA papers.

${ }^{51}$ NBCA: The Gynaecological Clinic, memorandum to branch clinics, February 1939, SA/FPA/Al/1, FPA papers.

52 NBCA: The Gynaecological Clinic, memorandum to branch clinics, February 1939, SA/FPA/Al/1, FPA papers.

${ }^{53}$ Kaarin Michaelsen. "Union Is Strength': The Medical Women's Federation and the Politics of Professionalism, 1917-30," Women and Work Culture c. 1850-1950, ed. Krista Cowman and Louise Jackson (London, 2017), 161-76.
} 
information and practice both in Britain and internationally. ${ }^{54}$ Many of the same women were also actively involved in the promotion of infertility work in National Birth Control Association clinics. For these women and others active in the family planning movement-including Stopes-family planning was as much about giving women control over their own bodies as about population limitation, and that desire to empower women fed easily into a support for research into the causes and remedies for infertility.

The year after the 1938 meeting, the National Birth Control Association changed its name to the Family Planning Association and broadened its constitution to include not only education about and dissemination of contraception but also the diagnosis and treatment of infertility (or "involuntary sterility"). This was not a "natural" development of the National Birth Control Association clinics' previous ad hoc treatment of a few infertility cases. Rather, it was the culmination of a series of politically charged debates about the relation of infertility to the perceived population crisis; changing public attitudes toward birth control during that crisis; and the existing gendered interpretation of infertility within the medical profession and society more broadly.

The expansion of National Birth Control Association clinic services to include gynecology and infertility was not universally embraced by members of the national board or by clinic secretaries and doctors. In April 1939, the association's secretary Margaret Pyke wrote to Sir Mark Grant-Sturgis, a council member of the Eugenics Society, which had given significant funds to the association since its inception, and an advocate of the expansion, explaining to him the need for tact: "It is quite a ticklish position nowadays between those who want to practically swamp b.c. [birth control] in all these other ologies and those who can see nothing beyond it! We have got to embrace the lot. ${ }^{\prime 55}$

Margaret Jackson, whose Exeter clinic had done pioneering work in diagnosing male and female infertility, was the loudest advocate of bringing "these other ologies" officially within the National Birth Control Association's orbit. Initial letters circularized to the branch offices from headquarters in early 1939 suggesting a new constitution and a change of name did not specifically mention infertility, instead stating that the association's women's health centers should provide advice on minor gynecological ailments and difficulties relating to the marriage relationship. It was Jackson who wrote to Spring Rice suggesting that the words "involuntary sterility" ought to be added to the new constitution, to which she responded, "We absolutely agree about this and are sorry that we omitted it." 56 A new document was drawn up for discussion at a special meeting held on 10 May 1939. At that meeting, Jackson made a strong case for change, saying that "she did not see why we should confine ourselves to birth control only. Marriage guidance and sterility should be stressed and encouraged. Women who come from a distance to the clinic would not be likely to return, and they should be treated then and there for minor gynaecological conditions." 57

\footnotetext{
${ }^{54}$ Caroline Rusterholz, "English Women Doctors, Contraception and Family Planning in Transnational Perspective (1930-1970)," Medical History 63, no. 2 (2019): 153-72; Rusterholz, Women's Medicine.

${ }^{55}$ M. Pyke to Sir M. Grant-Sturgis, 27 April 1939, SA/FPA/Al/2, FPA papers.

${ }^{56}$ M. Spring Rice to M. Pyke, 3 May 1939, SA/FPA/Al/2, FPA papers.

${ }^{57}$ Minutes of 10 May 1939 extraordinary general meeting, FPA papers.
} 
While Jackson advocated for the official change of aims on the basis of the medical benefits it would provide for clinic patients, other participants in the special meeting framed their arguments around the financial benefits that would accrue from distancing the organization from the negative associations surrounding birth control, particularly in light of the perceived demographic crisis. Prior to the meeting, Margaret Pyke had argued that "in the greater part of the country the people they [our Organizers] approach simply think that we have as our main object the prevention of people having children; and, in view of the population statistics, this has a disastrous effect on the work. Both Treasurers report the same difficulty and say that it is increasing and, as we are already greatly in debt, this is an important consideration." 58

At the meeting, Lord Horder, a clinician who notably served as president of both the National Birth Control Association and the Eugenics Society, began by saying, in recognition of the opposition within the organization to a change of remit, that "he would not like to think that people accused us of being dragooned from our object by the pressure of the population question." Nonetheless, the fact was that people were increasingly charry of supporting an organization they perceived as enabling population decline. Horder was followed by the organization's treasurer, who argued that "she was trying to get 1,000 guinea members and was finding it difficult to put $b$. c. across to the intelligent public," as many saw it as "negative social work." Miss Holland, one of the regional organizers, endorsed this view: "As an Organiser the difficulties were much the same as those of the Money Raiser- she thought that a title which did not contain the words b.c. would be a help."59 The comments at the special meeting echoed the warning expressed three years earlier by C. P. Blacker that the low net reproduction rate meant that a demographic crisis was on the horizon, with dangerous consequences for the birth control movement: "This argument will be increasingly heard, and I am informed by the [National Birth Control Association's] organizers that it has already been used against them in criticism of the Association's 'negative' policy."60

The decision to change the name to the Family Planning Association has been characterized by Andrew as a "rebranding exercise," by which she means to signify "that not only was the FPA a new name, but it also presented a new communications strategy to reframe the organization's identity for 'consumers', investors, and other stakeholders."61 There is undoubtedly significant truth to this, and it is important to recognize the centrality of concerns about population decline to this process. In 1939, Spring Rice argued in an internal memorandum advocating for the constitutional change, "The tide of public opinion which has been steadily rising in our favour will inevitably turn when the threatening disaster [population decline] is fully realised, a disaster which at any moment may be hastened by the ravages of war. Let us, while there is still time, show the world what we really stand for, and boldly welcome all the opportunities which have been given us to help in the building of a healthy and happy democracy."62

\footnotetext{
${ }^{58}$ M. Pyke to Mr. Palmer, 28 April 1939, SA/FPA/Al/2, FPA papers.

${ }^{59}$ Minutes of 10 May 1939 extraordinary general meeting, SA/FPA/Al/2, FPA papers.

${ }^{60}$ C. P. Blacker, "The Eugenics Society and the NBCA," 22 September 1936, SA/FPA/Al/1, FPA papers.

${ }^{61}$ Andrew, "Reluctant Stork," 45.

${ }^{62}$ Memo by Margery Spring Rice, Arguments for Expansion, 28 April 1939, SA/FPA/Al/2, FPA papers.
} 
Britain never had a state-run pronatalist campaign in the 1930s to rival the policies of the French, Italian, or Scandinavian governments. It could be argued that this was because the British elite, influenced by the results of the 1911 "fertility census," believed-incorrectly, as Simon Szreter has argued - that Britain's problem was not a general depopulation crisis but a differential fertility crisis wherein the poor and unfit were continuing to breed like rabbits while the middle classes practiced family planning. ${ }^{63}$ Yet, as Richard Soloway has noted, the late 1930s did witness a "depopulation panic" in the popular press akin to that in other European countries - a panic fueled by the prognostications of eugenicists, which in turn influenced eugenic policy in the years to come. ${ }^{64}$ For people like Blacker, "positive" eugenics was a way of responding to the population crisis.

If the decision to "rebrand" the National Birth Control Association as the Family Planning Association and officially take on board the treatment of infertility and "minor gynaecological ailments" within the organization's remit was as much about fund-raising and staying ahead of the population crisis as it was about improving care for working-class women, feminist doctors within the association worked to ensure that the rebranding would not be merely superficial. In the years following the 1939 constitutional change, the association established a network for infertility research and investigation that would ultimately broaden popular understandings both of what was encompassed by the term "family planning" and of how infertility was perceived (and gendered) by the British and international medical establishment.

In 1943, the Family Planning Association set up an executive subcommittee to consider how the organization could make its impact felt in the field of sub-fertility. Crucially, the committee, chaired by the association's then president, Lord Horder, included several of the women doctors who had been most actively involved in sub-fertility work in the 1930s. In addition to Jackson, Joan Malleson, Margaret Moore White, and Kathleen Harding were among the initial appointed members. ${ }^{65}$ The women worked alongside a group of male gynecologists, including Aleck Bourne, Cedric Lane-Roberts, and Newcastle obstetrician Linton Snaith, who was particularly keen to expand infertility services in the north of England. (The association's policy was that clinics should be attended by women doctors, so while the female members actually worked in the association's clinics, their male colleagues dealt with infertility cases either in hospitals or private practice.) Although not a specialist in women's health, Dr. Annis Gillis of the Medical Women's Federation was coopted onto the committee. Her attendance was irregular, but her cooption suggested a recognition that sub-fertility was an issue where, as the federation put it, "medical women are particularly concerned in the public well-being." 66 Together,

\footnotetext{
${ }^{63}$ Szreter does not argue that Britain was facing a general population crisis in 1911. Rather, his critique is that, when the data are properly approached, they actually indicate that, across classes, Britons were not practicing modern family planning so much as continuing a practice, begun in the Victorian era, of using abstinence as a tool to space childbirth. Simon Szreter, Fertility, Class, and Gender in Britain, 1860-1940 (Cambridge, 1996).

${ }^{64}$ Richard A. Soloway, Demography and Degeneration: Eugenics and the Declining Birthrate in TwentiethCentury Britain (Chapel Hill, 2014), chap. 10.

${ }^{65}$ Although, like Jackson, not a fellow of the Royal College of Obstetricians and Gynaecologists, Malleson had a long-standing interest in birth control and gynecology.

66 "The Place of Family Planning in the National Health Service," Medical Women's Federation Journal, July 1950, SA/MWF/J/23/24/3, Medical Women's Federation papers, Wellcome Library, London.
} 
this group of doctors put together an agenda that encompassed fact-finding, publicity, research, and treatment.

They began with fact-finding. At their inaugural meeting in May 1943, they decided to circulate a questionnaire to local clinics about their current practice and their willingness to take on further infertility work. The questions posed are illuminating of the state of infertility treatment in the country. ${ }^{67}$ Clinics were asked if they had equipment for testing tubal patency; if not, did their local hospital have such facilities; and were they interested in acquiring such equipment and in receiving training in its use? They were asked similar questions about pathological facilities for semen analysis. Notably, given developments in the standardization of semen testing and classification in the 1930s, ${ }^{68}$ the sub-committee also enquired, "Do you think that the pathologist (a) has a good technique, and (b) would be agreeable to modify his technique to meet present day requirements." (The use of the male gender pronoun is conspicuous, as, at that time, the most experienced pathologist working with the association on semen analysis was a woman, Claire Harvey in Exeter.) Finally, clinics were asked whether they thought that both patients and the local medical community would welcome an expansion of their services in this direction-a key issue, given the importance of local connections to the financial and operating success of the association's clinics through the period. ${ }^{69}$

The results of the survey suggested that few clinics outside of London and Exeter had any facilities for infertility investigation, and that there was little enthusiasm among clinic doctors to undertake training in this direction. Nonetheless, the subcommittee pushed ahead, working seemingly on the belief that, if you build it, they will come. In October 1943, they held a day-long training course for forty of the association's doctors, at which Harvey gave demonstrations in conducting pathological tests-a good turnout, particularly given wartime constraints. ${ }^{70}$ By 1951, the association's lists of clinics included asterisks beside those which either held special sub-fertility sessions or "carr[ied] out preliminary investigations and gave advice on childlessness, referring patients to hospitals for further treatment if necessary." To provide these services was a mark of honor, and the central office repeatedly encouraged more clinics to do so.

While the doctors were keen to promote tubal insufflation for both diagnostic and therapeutic reasons, their principal concern was to encourage seminological testing, which they did through conferences, literature, and ultimately the opening of the FPA Seminological Centre on Wimpole Street in Marylebone on 1 January 1945 - the first purpose-built semen testing laboratory in Britain.

Here the influence of feminist thinking on the sub-committee is clearly visible. An earlier generation of feminist "moral purity" activists led by Josephine Butler had focused on the injustice of female prostitutes being subjected to invasive investigations for venereal diseases and committed to lock hospitals when male clients were not subjected to the same coercive scrutiny by either the state or the medical

${ }^{67}$ Questionnaire circulated to clinics, 1943, SA/FPA/A5/103; also SA/MWF/J/23/24/3.

${ }^{68}$ F. T. Andrade-Rocha, "On the Origins of Semen Analysis: A Close Relationship with the History of the Reproductive Medicine,” Journal of Human Reproductive Science 10, no. 4 (2017): 242-55.

${ }^{69}$ Dale and Fisher, "Contrasting Municipal Responses"; Jones, "Family Planning Clinics."

${ }^{70}$ Minutes of the Sub-Fertility committee, 2 December 1943, SA/FPA/A5/102, FPA papers. 
profession. ${ }^{71}$ Now a group of prominent women doctors again sought to upend a system that submitted the female body to intrusive and often unnecessary scrutiny to treat a problem that was, as often as not, the "fault" of their male partners.

Their first step was to consider ways of persuading more husbands to submit to sub-fertility investigation. To this end, the committee agreed that new Family Planning Association sub-fertility sessions should be arranged via appointment, not by drop-in, and with adequate provisions for privacy. According to their minutes, while "there was a general opinion that husbands were much less unwilling than they used to be to go for seminal examinations . . . without these provisions, [Dr. Malleson] did not think it would be possible to get the husbands to go to a hospital."72

The committee also undertook to produce a popular booklet For Childless Wives, which, despite its title, was clearly meant to be read by both partners. ${ }^{73}$ The decision to go ahead with its publication in 1944, while wartime paper rationing was in effect, shows a commitment to publicizing this area of the association's work. Throughout the booklet, it is "the couple," not the wife, who is referred to as childless. The booklet is written in accessible, non-medical language, and the section on causes of infertility addresses both female and male factors. In discussing the male factor, it proclaims, "Sometimes, even with a perfectly healthy young husband, the sperms may be 'lazy', and if the journey to the egg happens to be particularly hard for any reason, the difficulties will be altogether too great," resulting in infertility. ${ }^{74}$ In a section entitled "What a Doctor Will Suggest," the booklet makes it clear that it is a husband's marital duty to submit to a semen analysis. It explains that the first step in an infertility investigation is normally an examination of the wife. "If all appears well. . . [the doctor] will arrange that the husband has a specimen of his semen examined at the laboratory." Only if this test shows that the sperms "are well up to standard," can a "doctor kno[w] that he is justified in making more elaborate investigations in the wife. Husbands should understand that this is the only proper way of proceeding." 75 The booklet ends with an admonition ostensibly directed to the wife but clearly intended for both partners: "The woman who is disappointed should not really ask for sympathy until she has consulted a doctor and undertaken every possible measure which he suggests." 76

In subsequent literature produced throughout the period, the association repeatedly emphasized the need to test both partners, to the extent that it became almost a mantra. For example, in response to a brief letter from one woman in 1950 asking to know more about the work of the association's sub-fertility clinics, the general secretary wrote back, "One very important point about the investigation and treatment of subfertility is that married couples must be treated as a couple, and as you will see from the enclosed memorandum, a great deal of trouble and

${ }^{71}$ Judith Walkowitz, "Male Vice and Feminist Virtue: Feminism and the Politics of Prostitution in Nineteenth-Century Britain," History Workshop 13, no. 1 (1982): 79-93; Judith Walkowitz, Prostitution in Victorian Society: Women, Class, and the State (Cambridge, 1982).

${ }^{72}$ Minutes of the Sub-Fertility committee, 19 August 1943, SA/FPA/A5/102, FPA papers.

${ }^{73}$ For Childless Wives: A Doctor Advises (London: FPA, 1944).

${ }^{74}$ For Childless Wives, 5.

${ }^{75}$ For Childless Wives, 10.

${ }^{76}$ For Childless Wives, 14. 
disappointment can be saved if the husband, as well as the wife, is investigated at an early stage." 77

The shift in the association's policies extended beyond private appointments for male patients and repeated exhortation to husbands. In 1944, the association devoted significant financial resources to establishing its new Seminological Centre, for the express purpose of running semen tests on the husbands in infertile couples. For the two decades after its opening, the center was the single largest line item in the national association's yearly accounts, even after the association stopped renting premises for the lab and moved it into the Sloane Street building, which it purchased in 1949. The center was headed by the German-born pathologist Hans Adolf Davidson, and employed three lab technicians in $1949 .{ }^{78}$ It ran approximately two thousand semen tests a year and charged hospitals that referred their patients to the center (a significant proportion of the patient base into the 1950s) a reduced fee. It also regularly trained pathologists from National Health Service hospitals and Family Planning Association centers for a modest fee, a decision that was motivated as much by the political motive of spreading knowledge of semen testing as by the financial incentive. Yet, despite the fact that Davidson also performed testicular biopsies and took on occasional work testing products for drug companies, the center did not reliably earn its keep.

Significantly, however, the association never seriously considered closing the center until the eventual growth of seminological testing facilities in National Health Service hospitals ultimately rendered its work superfluous. In a confidential memorandum written in the early 1950s, the executive noted, "The Sub-Fertility Centre is claimed to have considerable prestige-value for the Association," as "Sub-Fertility work counteracts the narrow view of family planning as consisting of contraception, and also provides a constructive aspect to the work of the FPA: it, therefore, reflects well on the association and the extent of its interests." 79 The center might have been costly, but it had tangible benefits both for patients and for the association.

The Family Planning Association's pioneering work did not, however, extend from diagnosis to treatment. When examination indicated female-factor infertility, women were still referred to a hospital gynecological unit. When male-factor infertility was indicated, couples were urged to adopt, or, occasionally, discretely referred to one of the few known practitioners of artificial insemination. The association's doctors might believe that the procedure was a valuable treatment for infertile couples, but only Margaret Jackson is known to have regularly practiced it in her clinic. ${ }^{80}$ For, while many in the association were motivated to help women in childless marriages obtain the children they so clearly craved, they were conscious that the support of others within the association was contingent on the more pragmatic analysis that infertility work boosted the reputation of the association and helped recruit donors. In contrast, artificial insemination was a deeply controversial procedure in

\footnotetext{
77 Arnold to E. Macolmson, 27 March 1950, FPA/A3/20/2, FPA papers.

${ }^{78}$ Correspondence, papers, 1944-49: Sub-Fertility Centre, FPA/A3/22, FPA papers. According to the clothing rationing coupons contained in this file, laboratory uniforms were ordered for Davidson, William Greenwood, Luela Lowy, and Miss Florence Ada Collin.

79 "Strictly confidential" memorandum filed with minutes of meeting of the Ad Hoc (Sub-Fertility Dept) reorganisation sub-committee [n.d., late 1952 or early 1953], FPA/A5/105, FPA papers.

80 "The Treatment of Involuntary Sterility," Lancet 243, no. 6310 (10 June 1944): 766-68.
} 
postwar Britain, and open endorsement of the procedure by the Family Planning Association would have courted controversy and alienated many of its supporters. The association's leadership was extremely up-front about the pragmatism of this approach. In December 1957, Mrs. Clifford Smith, the organization's general secretary, wrote, "The FPA as an Association has not pronounced officially on artificial insemination. As you know our own work is subject to so much misinterpretation arising either from genuine misunderstanding or from opposition to our policy that we should be foolish to add to our difficulty in getting on with the job by adopting an attitude to a controversial subject like AI." 81 That said, both the national office and doctors at local branches would occasionally respond to appeals for information about artificial insemination by referring patients to non-association practitioners, such as Mary Barton and Bernard Sandler, who were known to perform the procedure. ${ }^{82}$

The other substantial and time-consuming initiative that the association undertook in the field of sub-fertility was the establishment of an annual academic conference on the study of fertility in both humans and animals. The inaugural conference was held in Exeter in 1944 and hosted by Margaret Jackson. Members of the association's SubFertility Committee took turns hosting each successive conference with the subvention of the association until 1950, when a newly constituted independent body, the Society for the Study of Fertility, was set up to take control of the event moving forward. It remained the key British academic organization for andrologists, endocrinologists, gynecologists, and zoologists interested in fertility research until 2001, when it amalgamated with the Journals of Reproduction and Fertility Ltd to form the Society for Reproduction and Fertility. What became its annual conference was a significant contribution to the creation of the academic field of infertility research in the United Kingdom.

The Family Planning Association's work in the field of infertility was targeted around the dual ends of encouraging the investigation of male-factor infertilitywith the aim of preventing unnecessary invasive investigations and surgeries on female patients - and filling a void in the provision of infertility services for both men and women in National Health Service hospitals. Their advocacy for greater infertility provision within the National Health Service is one area where the importance of a genuine concern for women's welfare-as opposed merely to a concern for the optics of appearing to support the positive side of family planning-is most clearly to the fore. In 1944, Churchill's coalition government appointed members to a Royal Commission on Population, which held extensive hearings and convened several fact-finding subcommittees before issuing its report in 1949. One such was the Biological and Medical Committee, one of whose eight members was C. P. Blacker. His presence would have guaranteed that the committee was well informed about the Family Planning Association's work on infertility. The body's final report reflects the association's input and deserves to be quoted at length:

It is only recently that the male factor in infecundity has been adequately appreciated. The growing interest in the subject is reflected in the fact that since about 1936, the

${ }^{81}$ Clifford-Smith (FPA General-Secretary) to Mrs. Ethel Clark of Sheffield, 16 December 1957, SA/ FPA/A3/2, FPA papers

${ }^{82}$ Model Letters, SA/FPA/Al/15, box 4, FPA papers. 
voluntary birth control clinics, of which there were about 30 before the war, have been paying more attention than formerly to problems of infecundity and most of them now pay as much attention to this aspect of their work as to their original purpose of giving advice on contraception... The Committee believe that the best chance of stimulating progress lies in the encouragement and development of special fertility clinics on a regional basis as part of the Health Service of the country, these centres to be so designed as to secure at each centre the expert investigation of both the male and female sides of the problem. ${ }^{83}$

The association again pushed for expanded state-funded infertility services in its evidentiary submission to the Royal Commission on Marriage and Divorce in 1951: "Advice on sub-fertility, especially on male infertility, is frequently difficult to obtain and facilities should be far more widespread. The FPA therefore hopes that the Royal Commission on Marriage and Divorce will agree with the Royal Commission on Population that 'public policy should assume and seek to encourage the spread of voluntary parenthood." ${ }^{34}$

The Family Planning Association did not attempt to leverage its support for greater state provision of infertility care in its fund-raising campaigns, which make little mention of either Royal Commission report. Rather, their approach reflected a genuine commitment to expanding access to infertility investigation and treatment for both partners in an infertile couple. A decade later, Family Planning Association doctors were still looking for ways to encourage NHS provision of infertility treatment, as when the association's medical secretary, Eleanor Mears, proposed setting up a special unit in London to train doctors-both Family Planning Association and National Health Service-in the diagnosis and treatment of infertility. ${ }^{85}$ (The proposal was not ultimately taken up, likely for financial reasons.)

While the organization's ultimate aim was to encourage the National Health Service to take up infertility treatment, in the short term it was willing to work with local government to deliver care in its own facilities. A January 1957 memorandum notes, "[Minister of Health] Wakefield was very pleased to hear that the FPA wanted to do more for infertile couples and offered extended use of Local Authority premises for Sub-Fertility sessions. He said this aspect of our work would strengthen his hand with his Health Committee, some members of which always raised objections to our using L/A premises [for birth control]." 86 As infertility treatment on the NHS expanded in the 1960s and 1970s, the work of the association's infertility diagnosis gradually diminished; however, for several decades after the establishment of the National Health Service, select association clinics remained an important component of the system for diagnosing and treating infertility in Britain. ${ }^{87}$

${ }^{83}$ Royal Commission on Population, Report, 1949, Cmd. 7695, at 192. Filed in FPA Sub-Fertility Committee minutes, 8 May 1950, SA/FPA/A5/102, FPA papers.

${ }^{84}$ Irene James to Mable Rew, 29 February1952, SA/MWF/J/23/24/3, FPA papers. James, the general secretary of the FPA, sent Rew a copy of the evidence that the FPA sent to the Royal Commission on Marriage and Divorce on 14 December 1951. The report was an enclosure in that correspondence.

${ }^{85}$ Mears, memorandum of the Medical Advisory Council [of the FPA] re: Subfertility and the FPA, 24 September 1964, SA/FPA/A3/23, FPA papers.

${ }^{86}$ Unsigned memorandum, January 1957, SA/FPA/A3/23, FPA papers.

87 While Exeter was admittedly exceptional given Jackson and Harvey's international standing in the field of infertility research and treatment, it is notable that, until Jackson's retirement in 1963, the 


\section{CONCLUSION}

The National Birth Control Association name change and the expansion of its stated aims in 1939 began in part as a rebranding exercise to shore up the organization's support base in the face of the perceived coming demographic crisis. The continued importance of public relations remained a key aspect of the Family Planning Association's framing of its infertility work up to the government's takeover of its clinics in 1974. Yet, the association's infertility work was not just "for show." As Mears wrote in 1963, discussing the genesis of the Seminological Centre, "The clinic was set up, of course, in the days when the husband was being ignored, to draw attention to the need to investigate him too, and to make facilities available to do so. This was an excellent idea, but to my mind is incomplete." 88 Family Planning Association clinics continued to offer infertility diagnosis up until 1974, when the reorganization of the National Health Service to incorporate family planning services and the free provision of contraceptives led to the phased transfer of more than one thousand Family Planning Association clinics and domiciliary services to the area health authorities. ${ }^{89}$ Even the transfer of the association's clinics to the National Health Service did not end the organization's interest in infertility work, as evidenced by their 1982 submission to the Warnock committee cited at the beginning of this article.

Highlighting the crucial role of politics in the expansion of infertility treatment in the mid-twentieth century not only reframes our understanding of the history of infertility but can also give context to the current crisis of support for funding infertility treatment in the United Kingdom. Once attention has been drawn to the links between social context, political agency, and infertility medicine, it becomes easier to recognize the historical contingency behind the view expressed by the chief of National Health Service England that in vitro fertilization treatments are unaffordable, and the view recently expressed by the Family Planning Association that sex education curricula in schools should not include discussions of women's biological clocks and the risks associated with delaying pregnancy. ${ }^{90}$ Attitudes toward infertility are not now, nor have they ever been, apolitical.

South Western Regional Hospital Board paid a grant to the Exeter Family Planning Clinic to cover her salary for her work on infertility patients referred to the clinic by the local hospital. See Exeter 19521966, SA/FPA/A4/B6.2, FPA papers.

${ }^{88}$ Dr. Eleanor Mears, FPA Medical Secretary, memorandum of the Medical Advisory Council [of the FPA] re: Subfertility and the FPA, 24 September 1964, SA/FPA/A3/23, FPA papers.

89 "A History of Family Planning Services Factsheet," Family Planning Association (website), accessed 5 February 2020, https://www.fpa.org.uk/factsheets/history-family-planning-services.

${ }^{90}$ Paul Gallagher, "NHS England Chief Suggests Erosion of IVF Funding Set to Continue," iNews, 1 July 2018. https://inews.co.uk/news/health/nhs-chief-suggests-erosion-of-ivf-funding-on-nhs-set-to-continue. On the Family Planning Association, see above, note 2. In another recent related development that highlights the politics of reproductive medicine, feminist activists have shown hostility to exogenesis technologies intended to help premature babies and infertile women for fear that these might be used by abortion opponents to argue against fetal termination on the grounds of proved extrauterine viability. See Sarah DiGregorio, “Artificial Wombs Aren’t a Sci-Fi Horror Story,” Slate, 30 January 2020, https:// slate.com/technology/2020/01/artificial-wombs-science-fiction-pregnancy-premature.html?fbclid=IwAR0FzSr0SGguFNh6RZGj9vWFGaMKNeDXW01tr-uJpEuM9CMLUjgVPhcDFWA. 